\title{
The therapeutic benefits of natural therapeutic factors in Baile Tusnad for the rehabilitation of patients with Parkinson's disease
}

\author{
Gabriela Dogaru12, Denisa Muresan ${ }^{1}$, Ioana Stanescu², Marieta Motricala ${ }^{3}$, Molnár Ákos ${ }^{3}$
}

1. "Iuliu Hatieganu" University of Medicine and Pharmacy Cluj-Napoca, Romania,

2. Clinical Rehabilitation Hospital Cluj-Napoca, Romania

3. Tusnad Spa Complex S.A., Baile Tusnad, Romania dogarugabrielaumfcj@yahoo.ro

\section{ABSTRACT}

Introduction. Primary Parkinson's disease is the consequence of a degenerative process, being a progressive disease of the central nervous system. It is the second cause of motor disability in elderly patients, after stroke, and the second most frequent neurodegenerative disease, after Alzheimer's disease. Băile Tuşnad spa resort in Romania is recognized for its role in primary and secondary prophylaxis, as well as in the rehabilitation treatment of cardiovascular, neurological, renal, digestive, rheumatic diseases, through the presence of natural therapeutic factors specific to this area: carbonated mineral waters through their peripheral and central vasodilator effects, mofettes, natural carbon dioxide emissions, and a stimulating bioclimate. Objectives. This study aimed to assess the clinical efficiency of natural therapeutic factors in Baile Tusnad in order to continue the rehabilitation treatment of patients with Parkinson's disease in a spa and climatic resort. Methods. The study included 17 patients with Parkinson's disease Hoehn-Yahr stages 1-3, 5 women and 12 men, at the Treatment Facility of the Tusnad Spa Complex S.A., in the period April-December 2014. The patients were aged between 40 and 75 years. The clinical study was a prospective longitudinal analysis. Patients underwent rehabilitation treatment consisting of carbonated mineral water baths for 15 minutes, aerotherapy for 30 minutes daily, massotherapy, kinesiotherapy, performed daily for 16 days. Each patient was clinically assessed before and after treatment using the TINETTI Gait and Balance Scale, the 10-m walk test, the Webster Scale, the Quality of Life Scale, adverse reactions. Descriptive statistics at the two time points, before and after treatment, was performed using the specific module of the Data Analysis component Descriptive Statistics. For each separate scale, the T-test for the comparison of the means of paired samples was applied. Results. At the end of treatment, an improvement of the walking distance and speed, a statistically significant improvement of gait was observed, $p<0.05$. Statistically significant results $\mathrm{p}<0.05$ were also obtained for balance. The Webster Scale, which examines the limits of movement and autonomy (16.52 vs 12.58 ), showed a p value $<0.05$. When assessing the Quality of Life Scale (69.82 vs 77), a statistically significant p value $<0.05$ was obtained. There were no side reactions to the treatment applied. Conclusions. Natural therapeutic factors, i.e., carbonated mineral water baths and aerotherapy, along with kinesiotherapy, indicated for the rehabilitation treatment of patients with Parkinson's disease, influenced the clinical and functional picture, determining a significant improvement of the quality of walking and balance, an increase of independence and quality of life, including through the social interrelations created during the rehabilitation treatment in Baile Tusnad spa resort.

Key words: Parkinson’s disease, carbonated mineral water, medical rehabilitation 
Introduction. Parkinson's disease is a progressive degenerative neurological disorder, which usually develops after the age of 50. It clinically manifests by the association of at least two of the three signs: rest tremor, rigidity and brady/akinesia. The main but not exclusive lesion of this disease is a degeneration of dopaminergic cells in the locus niger, with the presence of Lewy bodies. A progressive loss of dopaminergic neurons, which represent the nigrostriatal pathway, occurs [1].

Parkinson's disease is the second cause of motor disability in elderly patients (after cerebrovascular accidents), being at the same time the second most frequent neurodegenerative disease, after Alzheimer's disease [1].

There is currently no curative treatment for Parkinson's disease, but drug treatment helps in improving symptoms. In addition to drug treatment, medical rehabilitation treatment both in specialized medical units and in spa resorts is particularly important for function improvement in patients.

Thus, Băile Tuşnad spa resort represents a favorable environment for rehabilitation in neurological disorders due to treatment with physical factors, kinesiotherapy, hydrothermal therapy performed in the treatment facility, as well as through the presence of natural therapeutic factors specific to this area: carbonated mineral water, mofettes, a stimulating, toning, sparing bioclimate, which are used for rehabilitation treatment [2, 3].

This study aimed to assess the clinical efficiency of natural therapeutic factors in Baile Tusnad in order to continue the rehabilitation treatment of patients with Parkinson's disease in a spa and climatic resort [4].

\section{Material and method}

The study included 17 patients aged between 40 and 75 years, at the Treatment Facility of the Tusnad Spa Complex S.A. The study was conducted from April to December 2014. The study group comprised both female and male patients, 5 women and 12 men. The patients' informed consent was obtained before their inclusion in the study. The study was approved by the Ethics Committee of the University of Medicine and Pharmacy Cluj-Napoca. This was a prospective longitudinal analysis.

The study inclusion criteria were patients with Parkinson's disease stages 1-3: 3 patients with stage 1, 9 patients with stage 2 , and 5 patients with stage 3 . The exclusion criteria were patients with Parkinson's disease stages 4 and 5 , patients with contraindications of spa treatment, with epilepsy, mental disorders, patients with contraindications of carbonated mineral water baths. The patients underwent rehabilitation treatment consisting of carbonated mineral water baths for 15 minutes, aerotherapy for 30 minutes daily, massotherapy, kinesiotherapy, performed daily for 16 days. Carbonated mineral water baths were performed in individual bathtubs. The water temperature was $32^{\circ} \mathrm{C}$. Treatment included massage of the cervico-dorso-lumbar spine, which was antalgic, decontracturing with a sedative effect, myorelaxant to maintain tissue elasticity and availability to effort. Effleurage and vibrations were the massage techniques used. The duration of a procedure was 15-20 minutes, daily.

As part of kinesiotherapy, passive, active and assisted active mobilizations of the segments involved in walking were performed, as well as neuroproprioceptive facilitation techniques across the entire range of motion. Walking while increasing upper limb swinging, which also facilitates the recovery of balance, was trained.

To improve movement speed, sensory stimuli were used: crying, clapping to maintain the patient's attention throughout the kinesiotherapy session. Knot's method was employed, which is also termed the pumping or rhythmic technique, involving the passive mobilization of a segment across its entire 
range of motion, performed several times, then the active rhythmic execution of the movement by the patient. Gradually, an improvement in the speed of initiation of the active movement was observed. For the recovery of the walking speed, the treadmill was used.

Reeducation of breathing involved the training of effortless prolonged breathing and an adequate breathing rhythm, the establishment of a balance between inspiration and expiration, an increase of respiratory capacity and the training of diaphragmatic breathing.

Kinesiotherapy sessions were conducted daily for 30 minutes, during 16 days, keeping in mind that patients with Parkinson's disease get tired quickly.

Throughout the duration of treatment, patients also received anti-Parkinson drug therapy.

Each patient was clinically assessed before treatment, on day 1 , and at the end of treatment, on day 16, using the Tinetti Gait and Balance Scale, the 10-m walk test, the Webster Scale, the Quality of Life Scale and adverse reactions.

The Tinetti Scale analyzes the patient's gait and capacity to maintain balance. For the determination of gait parameters, the patient is in standing position and walks through the room (with or without assistance), and the assessment of balance is initiated with the patient in sitting position. The total score is represented by the sum of gait and balance scores. The Webster Scale examines the limits of movement and autonomy with a score divided into three groups depending on severity. The 10 parameters are added up for the interpretation of the scale. The minimum score is 0 and the maximum score is 30 . The higher the score, the greater the severity and the disability of the disease are. For the $10-\mathrm{m}$ walk test, the patient is instructed to walk at a speed that he/she considers to be comfortable and to use any kind of support he/she needs.
The time required to walk the 10 meter distance is counted, based on which the walking speed can be calculated. The Quality of Life Scale is composed of 16 parameters (items). The instrument used will be the sum of the 16 items, resulting in the final score. Each parameter includes a number that indicates the patient's satisfaction/dissatisfaction at that time.

Statistical analysis evidenced statistically significant differences between the mean values of the scales before and after treatment. Data were collected and analyzed using the Microsoft Excel 2007 application. Descriptive statistics was performed in the group of patients before and after treatment, using the specific module of the Data Analysis component - Descriptive Statistics. For each separate scale, the T-test for the comparison of the means of paired samples was applied. The statistical significance threshold used was $\mathrm{p}<0.05$. The results were expressed via graphical representations such as columns and pie charts.

\section{Results}

\section{A. Incidence of Parkinson's disease by age groups}

The age of the group ranged between 40 and 75 years, with a mean age of 69 years. According to epidemiology, it is known that after the age of 65, Parkinson's disease affects a remarkable proportion of the population.

\section{B. Incidence of Parkinson's disease by sex groups}

The group included both female and male patients, 5 women and 12 men. The incidence of Parkinson's disease by sex groups shows a $71 \%$ predominance of the male sex. According to epidemiological data, Parkinson's disease develops in both sexes, with a slight prevalence in the male sex (Fig. 1). 


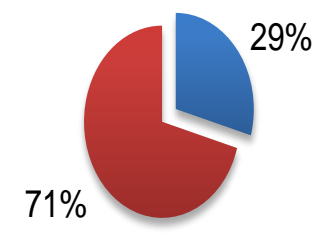

$$
\begin{aligned}
& \text { Fem } \\
& \text { ei }
\end{aligned}
$$

Fig. 1. Incidence of Parkinson's disease by sex groups

C. Incidence of Parkinson's disease according to Hoehn-Yahr stages 1-3

Considering Hoehn-Yahr staging of Parkinson's disease, the group included 3 patients with stage 1, 9 patients with stage 2, and 5 patients with stage 3 . Thus, a 53\% predominance of stage 2 can be seen, in which symptoms are bilateral, with low to moderate disability and the involvement of gait and posture in particular (Fig. 2).

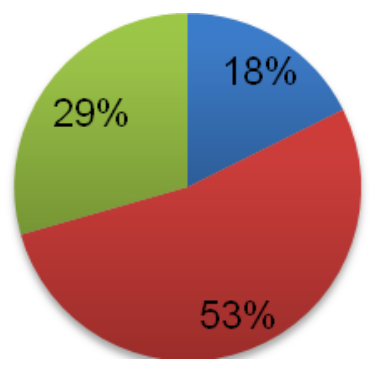

- Stadiul I

- Stadiul II

- Stadiul III

Fig. 2. Incidence of Parkinson's disease by stages

\section{Influence of the treatment of Parkinson's disease on gait and balance, assessed using the Tinetti Scale}

Regarding the Tinetti Scale, the mean value on completion of treatment, on day 16, the mean value increased by slightly more than 8 points, scoring 18. Thus, an important increase in the mean score from the initial to the final day can be observed in patients with Parkinson's disease (Fig. 3).

day 1 of treatment was 9.94. After the

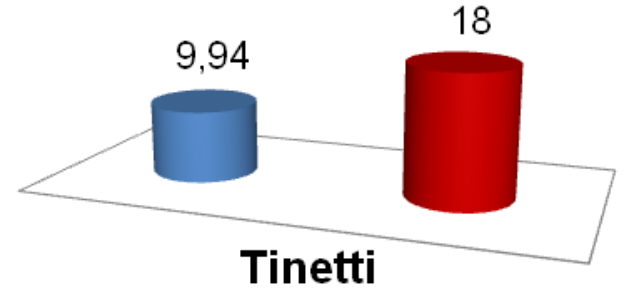

- Ziua 1

- Ziua 16

Fig. 3. Graphical representation of the means before and after treatment for the Tinetti Scale 
When comparing by the T-test the means of paired samples before and after treatment (9.94 vs 18), the $p$ value obtained was lower than 0.05 ( $p=0.000000000018$ ). Thus, the mean of the Tinetti Scale after treatment was significantly higher than the mean of the Tinetti Scale before treatment.
According to the data obtained for the Tinetti Gait and Balance Scale, there was a significant difference between days 1 and 16 of treatment, evidencing a special improvement of balance and gait in patients with Parkinson's disease included in the study group (Table 1).

\begin{tabular}{|c|c|c|}
\hline \multicolumn{2}{|c|}{ T-Test: Tinetti Scale } & \\
\hline Mean & Day 1 & Day 16 \\
\hline Variance & 9.941176471 & 18 \\
\hline Observations & 21.80882353 & 22 \\
\hline Pearson Correlation & 17 & 17 \\
\hline Hypothesized Mean Difference & 0.9073601 & \\
\hline Df & 0 & \\
\hline t Stat & 16 & \\
\hline P(T<=t) one-tail & -16.49286187 & \\
\hline t Critical one-tail & 0.00000000000914 & \\
\hline P(T<=t) two-tail & 1.745883676 & \\
\hline t Critical two-tail & 0.00000000001827 & \\
\hline & 2.119905299 & \\
\hline
\end{tabular}

Table 1. T-test performed for the Tinetti Scale

\section{E. Influence of the treatment of}

Parkinson's disease on the limits of movement and autonomy assessed using the Webster Scale

Regarding the Webster Scale, the mean value on day 1 of treatment was 16.52. After the completion of treatment, on day 16 , the mean value decreased by almost 4 points, scoring 12.58. Thus, an important decrease of the mean score from the initial to the final day of treatment can be seen in patients with Parkinson's disease (Fig. 4).

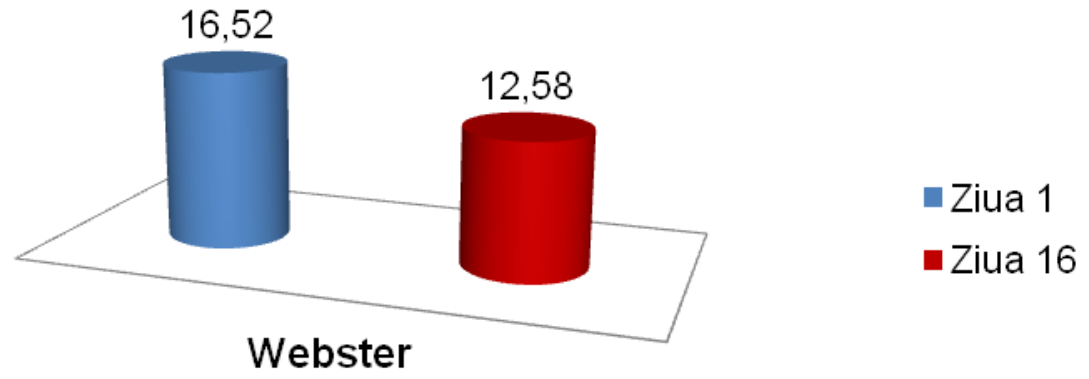

Fig. 4. Graphical representation of the means before and after treatment for the Webster Scale

When comparing by the T-test the means of paired samples before and after treatment (16.52 vs 12.58), the $\mathrm{p}$ value obtained was lower than $0.05(p=0.000000015)$. Thus, the mean of the Webster Scale after treatment was significantly lower than the mean of the
Webster Scale before treatment. According to the data obtained for the Webster Scale, which analyzes the limits of movement and autonomy in patients with Parkinson's disease, there was a significant difference between days 1 and 16 of treatment, evidencing a slight increase in the autonomy and clinical function of patients with 
Parkinson's disease included in the study group (Table 2).

\begin{tabular}{|l|r|r|}
\hline T-Test: Webster Scale & Day 1 & Day 16 \\
\hline Mean & 16.52941176 & 12.58824 \\
\hline Variance & 23.63970588 & 24.50735 \\
\hline Observations & 17 & 17 \\
\hline Pearson Correlation & 0.949604417 & \\
\hline Hypothesized Mean Difference & 0 & \\
\hline Df & 16 & \\
\hline t Stat & 10.4161158 & \\
\hline P(T<=t) one-tail & 0.0000000078 & \\
\hline t Critical one-tail & 1.745883676 & \\
\hline P(T<=t) two-tail & 0.00000001553120 & \\
\hline t Critical two-tail & 2.119905299 & \\
\hline
\end{tabular}

Table 2. T-test performed for the Webster Scale

\section{F. Influence of the treatment of Parkinson's disease on the walking time assessed using the 10 -m walk test}

Regarding the 10-m walk test expressed in seconds, the mean value on day 1 of treatment was 14.15 seconds. After the completion of treatment, on day 16, the mean value decreased by about 2 seconds, being 12.34 seconds. Thus, a decrease in the mean walking time over the given distance from the initial to the final day of treatment was found in patients with Parkinson's disease (Fig. 5).

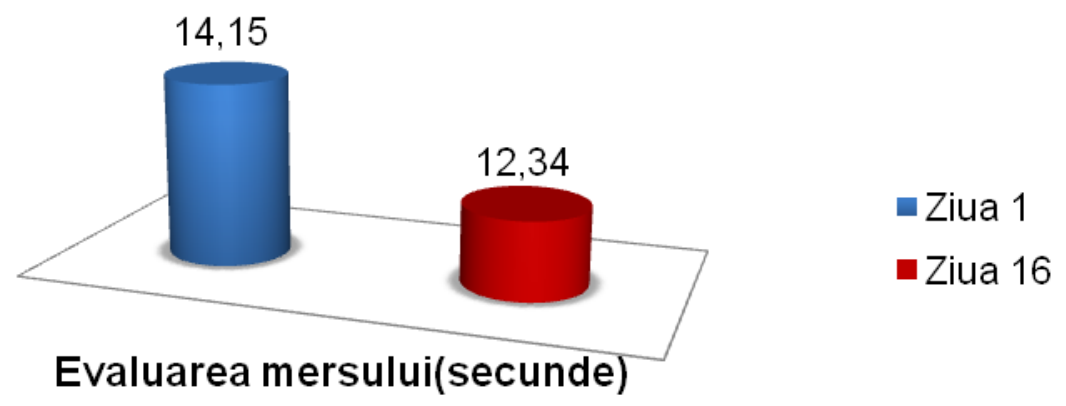

Fig. 5. Graphical representation of the means before and after treatment for the 10 -m walk test (seconds)

When comparing by the T-test the means of paired samples before and after treatment (14.15 vs 12.34), the $\mathrm{p}$ value obtained was lower than 0.05 ( $\mathrm{p}=0.0000000013)$. Thus, the mean of the $10-\mathrm{m}$ walk test after treatment was significantly lower than the mean of the $10-\mathrm{m}$ walk test before treatment. According to the data obtained for the $10-\mathrm{m}$ walk test, which assesses mobility limitations during daily activities, there was a significant difference between days 1 and 16 of treatment. An important decrease in the walking time, with a reduction of limitations for daily activities was evidenced in patients with Parkinson's disease included in the study group (Table 3). 


\begin{tabular}{|c|c|c|}
\hline \multicolumn{2}{|l|}{ T-Test: 10-m Walk Test } & \\
\hline & Day 1 & Day 16 \\
\hline Mean & 14.15 & 12.34118 \\
\hline Variance & 9.453125 & 9.510074 \\
\hline Observations & 17 & 17 \\
\hline Pearson Correlation & 0.980818655 & \\
\hline Hypothesized Mean Difference & 0 & \\
\hline $\mathrm{Df}$ & 16 & \\
\hline t Stat & 12.36446325 & \\
\hline $\mathrm{P}(\mathrm{T}<=\mathrm{t})$ one-tail & 0.000000000666076 & \\
\hline t Critical one-tail & 1.745883676 & \\
\hline $\mathrm{P}(\mathrm{T}<=\mathrm{t})$ two-tail & 0.00000000133215 & \\
\hline t Critical two-tail & 2.119905299 & \\
\hline
\end{tabular}

Table 3. T-test performed for the 10 -m walk test

\section{G. Influence of the treatment of Parkinson's disease on quality of life assessed using the Quality of Life Scale}

Regarding the Quality of Life Scale, the mean value on day 1 of treatment was 69.82. After the completion of treatment, on day 16 , the

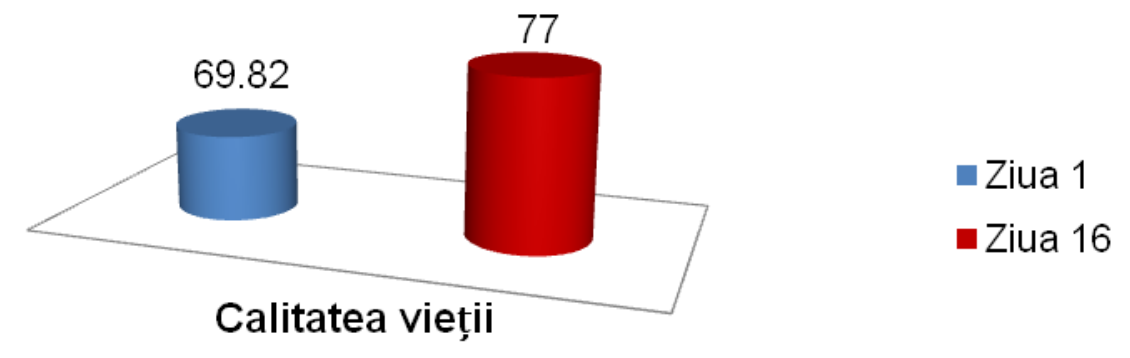

Fig. 6. Graphical representation of the means before and after treatment for the Quality of Life

Scale

When comparing by the T-test the means of paired samples before and after treatment (69.82 vs 77), the $p$ value obtained was lower than 0.05 ( $\mathrm{p}=0.000000000099)$. Thus, the mean of the Quality of Life Scale after treatment was significantly higher than the mean of the Quality of Life Scale before treatment. According to the data obtained for the Quality of Life Scale, which analyzes a person's independence during daily activities and socioprofessional integration, there was a significant difference between days 1 and 16 of treatment. Thus, an obvious increase of independence and an improvement of social interrelations was mean value increased by slightly more than 7 points, scoring 77 . Thus, an important increase in the mean score from the initial to the final day of treatment was seen in patients with Parkinson's disease (Fig. 6). 


\begin{tabular}{|l|r|r|}
\hline T-Test: Quality of Life Scale & \\
\hline & Day 1 & \multicolumn{1}{|c|}{ Day 16 } \\
\hline Mean & 69.82352941 & 77 \\
\hline Variance & 114.1544118 & 132.375 \\
\hline Observations & 17 & 17 \\
\hline Pearson Correlation & 0.986353092 & \\
\hline Hypothesized Mean Difference & 0 & \\
\hline Df & 16 & \\
\hline $\mathrm{t}$ Stat & -14.74057908 & \\
\hline $\mathrm{P}(\mathrm{T}<=\mathrm{t})$ one-tail & 0.00000000004961 & \\
\hline $\mathrm{t}$ Critical one-tail & 1.745883676 & \\
\hline $\mathrm{P}(\mathrm{T}<=\mathrm{t})$ two-tail & 0.00000000009923 & \\
\hline $\mathrm{t}$ Critical two-tail & 2.119905299 & \\
\hline
\end{tabular}

Table 4. T-test performed for the Quality of Life Scale

\section{Discussions}

In the clinical picture of Parkinson's disease, gait, balance and walking speed disorders are identified, which induce during the disease evolution a significant decrease in the quality of life and independence of patients diagnosed with Parkinson's disease. We only included in the study patients with Hoehn-Yahr stages 1-3 because we wanted to focus on patients with moderate to advanced disability, not severe disability, which makes the patient completely dependent on external assistance.

Thus, we thought that the efficiency of natural therapeutic factors: carbonated mineral water baths and aerotherapy, along with kinesiotherapy and massotherapy might influence ambulation, balance, the walking speed and implicitly, autonomy during daily activities in patients with Parkinson's disease. The effects of carbonated mineral water baths include peripheral and cerebral vasodilation, evidenced by the action of carbon dioxide. It is known that carbon dioxide concentration in the mineral water bath is directly proportional to the vasodilator effect. Thus, an increase of blood flow with the stimulation of venous return occurs [5]. Hypotonic carbonated mineral waters are rich in chlorine, sodium, calcium, magnesium, iron oxides, with a total mineralization of 0.68-17.86 g/liter.
The patients of the study group also received anti-Parkinson drug therapy, and the influence of spa treatment on the patients' balance, gait, quality of life and autonomy had a satisfactory impact on the improvement of clinical and functional status in patients with Parkinson's disease. This can also be seen in the case of the results obtained using the assessment scales specific for these disorders monitored during the spa treatment period of 16 days.

Given the absence of specific research on this subject, no terms of comparison with other literature studies are available.

\section{Conclusions}

1. Following the results obtained, the objectives of the study conducted in Băile Tuşnad spa resort were attained, and a favorable evolution of the clinical and functional picture of patients with Parkinson's disease was evidenced.

2. At the end of treatment consisting of carbonated mineral water baths, aerotherapy, kinesiotherapy, massage for 16 days, an improvement of the walking distance, a statistically significant improvement of gait was observed, $\mathrm{p}<0.05$.

3 . Statistically significant results $(\mathrm{p}<0.05)$ were also obtained for balance. 
4. The Webster Scale, which examines the limits of movement and autonomy by comparing the means before and after treatment using the T-test for paired samples, showed a statistically significant $\mathrm{p}$ value $<0.05$.

5. The Quality of Life Scale evidenced a statistically significant $\mathrm{p}$ value $<0.05$.

6. An improvement of breathing in patients with Parkinson's disease was found due to an increase of thoracic mobility following aerotherapy performed daily during 16 days of treatment.

7. We mention the fact that patients attended treatment in Băile Tușnad for the third or fourth time.

8. It is extremely important to continue medical rehabilitation treatment, unless contraindications exist, in spa and climatic resorts, in a pleasant environment close to nature.

9. In the future, we aim to continue the research of natural therapeutic factors and their efficiency in Parkinson's disease.

\section{Bibliography}

1. Nemeș D., Amărcicăi E., Suciu O., Popa D., Caţan L., Surducan D. Fizioterapia în afecțiunile neurologice. Timişoara: LITO U.M.F.T. 2010; 87-4

2. Munteanu Constantin. Ape minerale terapeutice. Editura Balneară, Bucuresti, 2013

3. Constantin Munteanu, Delia Cinteza. Cercetarea științifică a factorilor naturali terapeutici. București: Editura Balneară; 2011

4. Gabriela Dogaru, Denisa Muresan, Marieta Motricala, Molnar Akos. Increasing the quality of life of patients with Parkinson's disease by treatment with natural therapeutic factors in Baile Tusnad. Abstract book. Balneo Research Journal 2016 Vol 7 (2):108 Congres ISMH 2016

5. Dogaru Gabriela, Radulescu Alexandru. Therapeutic effects of carbonated mineral waters in cardiovascular rehabilitation. Balneo Research Journal 2015, vol. 6 (1):36-49 